by a difference in live weight change between the two rations. The difference between breeds was approximately $4 \%$.

The efficiency and the milk energy equivalence were highly correlated with a difference between rations. The concentrate level and the allocation of concentrates to individuals have an influence on the relationships. Estimates of genetic parameters on different feeding systems are necessary for predicting the response to selection in different environments.

\title{
References
}

Conrad, H. R., A. D. Pratt \& J. W. Hibbs, 1964. Regulation of feed intake in dairy cows. 1. Change in importance of physical and physiological factors with increasing digestibility. Journal of Dairy Science 47: 54-62.

Freeman, A. E. 1975. Genetic variation in nutrition of dairy cattle. In: The effect of genetic variation on nutrition requirements of animals, Washington: 19-46.

Lamb, R. C., J. L. Walters, M. J. Andersen, R. D. Plowman, C. H. Mickelsen \& R. H. Miller, 1977. Effects of sire and interaction of sire with ration on efficiency of feed utilization by Holsteins. Journal of Diary Science 60: 1755-1767.

Miller, R. H., N. W. Hooven, J. W. Smith \& M. E. Creegan, 1972. Feed consumption differences among lactating cows. Journal of Dairy Science 55: 454-459.

Oldenbroek, J. K.. 1981. Economic evaluation of breed comparison. 32th Annual Meeting European Association for Animal Production, Zagreb.

Richardson, D. O., J. R. Owen, R. D. Plowman \& J. T. Miles, 1971. Importance of sire $\times$ ration interactions in production and feed intake traits of dairy cattle. Journal of Dairy Science 54: 1518-1525.

This synopsis is based on a doctoral thesis, Agricultural University, Wageningen, 1982. 148 pp., 22 figs, 61 tables, 6 appendices, 110 refs. English, Dutch summary.

Available as paper copy (order R002P, $f 30$ including postage) or microfiches (order R002M, $f$ 17,50 including postage) at: NARD, clo Pudoc, P.O. Box 4, 6700 AA Wageningen, Netherlands (telex $45015 \mathrm{blhwg} \mathrm{ll}$ ).

\section{Development of improved wheat genotypes in Zambia using incomplete resistance against rusts}

W. A. J. de Milliano (Guest, Department of Phytopathology, Agricultural University, Wageningen, Netherlands)

Accepted: 16 December 1983

Abstract. A low-budget breeding programme was used for developing fairly highyielding wheat lines within 6 years. The lines had a stable and incomplete resistance 
to stem rust, uniform resistance to leaf rust and a stable but adequate resistance to various pathogens and pests. The Zambian programme used locally selected parent genotypes with incomplete resistance to rusts. Crossing could be performed at a large scale with few personnel by means of a male gametocide.

Key-words: Ethrel, epidemiology, incomplete resistance, wheat improvement, rust races, Zambia.

Introduction. Zambia has less than 3000 ha of wheat and produces less than $10 \%$ of its wheat requirements (Hurd, 1981). Wheat can be produced in most parts of Zambia, but break-even yields cannot be obtained throughout the country. Soils, climate and relief affect yield levels. Actual and maximum yields have been increasing for all major cropping methods (irrigated, rain-fed, dambo and seepage wheat) since the $1950 \mathrm{~s}$. Further increase of wheat production for all major cropping methods seems feasible. Development of improved wheat genotypes is one of the activities to increase wheat production.

Materials and methods. The breeding programme (HRBP) was started by FAO (Robinson \& Chiarappa, 1977) and is since 1979 supported by DGIS of the Netherlands. Use was made of local facilities (finance, personnel, infrastructure); the budget was very low; there were few personnel. The materials and methods applied were to some extent the results of a development process based on local conditions and local requirements (farmers, input levels). Studies were made of wheat and its diseases and pests, in particular the agronomic performance of the parent genotypes, the epidemiology of stem rust (Puccinia graminis) and leaf rust ( $P$. recondita) and the importance of helminthosporium (Helminthosporium sativum).

It was attempted to avoid differential resistance (Van der Plank, 1968; Robinson, 1976). Some 34 parent genotypes and later groups of offspring were crossed by using the male gametocide 2-chloroethanophosphonic acid (Ethrel). The parent genotypes all had incomplete resistance to stem and leaf rust. Several genotypes were very susceptible to rusts. All genotypes were susceptible to helminthosporium.

Results. Terminal stem rust severities were higher during the rainy season (October to March) than during the irrigation season (April to November), except for very susceptible genotypes. High severities occurred especially at lower altitudes, and might occur more frequently with an increase in wheat area. Stem rust caused a mean yield loss of $15 \%$ for a terminal severity on the stem of $10 \%$ (James' Scale; James, 1971). All yield components were influenced. Tolerance had no practical importance. A good estimate of yield loss could be made by various approaches including simple regression. Race shifts were infrequent in Zambia but frequent in for example Kenya.

Leaf rust occurred more frequently than stem rust but only few genotypes were very susceptible and most genotypes had a reduction in kernel weight of $<5 \%$. Spontaneous epidemics began in February. Severities $>10 \%$ occurred in late 
April on rain-fed and in late June on irrigated wheat. Kernel weight was the only yield component to be significantly influenced after an early onset of the epidemics. Different race populations are present in neighbouring countries, which may reach Zambia by air.

Postponement of sowing to May served as a method to escape from high leaf and stem rust severities during the irrigation season.

After application of Ethrel, cross-fertilization occurred in several genotypes by open pollination and large quantities of cross-fertilized seed were produced. Crossing by means of Ethrel was useful during the cool and dry irrigation season, but was inefficient during the warm and wet rainy season.

Selection for a high-ranking mean yield was effective provided stem rust was present and severities averaged over genotypes were at least $8 \%$. Selection for high yield under high input conditions did not lead to 'stable' yield. Differential resistance occurred in genotypes with incomplete resistance irrespective of the level of the relative resistance.

Suitable lines for irrigated production were produced within five years by means of different breeding scenarios. Nine HRBP lines were admitted to the National Test (pre-registration trials) in 1980 and 19 HRBP lines in 1981. HRBP lines combined relatively high yield with comparatively wide adaptability, had a 'stable' and incomplete resistance to stem rust; they possibly had an uniform and incomplete resistance to leaf rust, incomplete but adequate resistance to various pests and diseases and a good baking quality. Under rain-fed conditions resistance to helminthosporium and tolerance to low $\mathrm{pH}$ needed improvement and yields remained below the target yield of $2 \mathrm{t} / \mathrm{ha}$.

Scenarios with two crossing generations tended to produce a higher number of acceptable lines for pre-registration than scenarios with one crossing generation. Sifting was not a useful method of selection. Fast-developing genotypes tended to have high helminthosporium severities during the rainy season.

Discussion and conclusions. Considering the frequency of occurrence of stem and leaf rust and yield losses, selection criteria suggested for Zambia are: a terminal severity on the stem (excluding leaf blades) of stem rust of $<5 \%$ and a relative resistance $>0.80$; a terminal rust severity on the lower leaves of $<10 \%$ and a relative resistance $>0.80$.

At present, the relatively small area of rain-fed wheat is reached by the rusts in February, and the irrigated wheat in June. Since these small targets are reached by inoculum, a larger target would certainly be reached, perhaps even at an earlier date. Differences in source-target relations are expected between areas in the central and southern part of Zambia and areas in the northern part. The great distance between source and target, the relatively small area of the sources and the vagaries of the weather during spore transportation may explain the variability in stem rust occurrence.

As there are distinct differences in requirements for rain-fed and for irrigated wheat, breeding and selection in separate gene pools may be more efficient than using one gene pool only. 
There is a limited scope for improvement of wheat production when well-designed research efforts are made. The costs of the necessary infrastructural investments have to be weighted against the benefits of improved wheat production at the regional level.

\title{
References
}

Hurd, E. A., 1981. Status of research and production, Zambia. In: J. A. Toogood (Ed.), Proceedings Wheat Workshop (Mount Makulu Research Station, Chilanga) 19-20.

James, W. C., 1971. An illustrated series of assessment keys for plant diseases, their preparation and usage. Canadian Plant Disease Surveys 51: 39-54.

Robinson, R. A., 1976. Plant pathosystems. Advanced series in agricultural sciences 3. Springer. Berlin. $184 \mathrm{pp}$.

Robinson, R. A. \& L. Chiarappa, 1977. The International Programme on Horizontal Resistance. FAO Plant Protection Bulletin 25: 197-200.

Van der Plank, J. E., 1968. Disease resistance in plants. Academic Press, New York/San Francisco/London, $206 \mathrm{pp}$.

This synopsis is based on a doctoral thesis entitled 'Improvement of wheat in Zambia using incomplete resistance against rusts', Agricultural University, Wageningen, 1983. ix +156 pp., 28 figs., 54 tables, 230 refs. English, Dutch summary.

Available as paper copy (order R003P, $f 30$ including postage) or microfiches (order R003M, $f 17.50$ including postage) at: NARD, c/o Pudoc, P.O. Box 4, $6700 \mathrm{AA}$ Wageningen, Netherlands (telex 45015 blhwg nl).

\section{The African catfish - A new species for aquaculture}

H. Hogendoorn (Dept. of Fish Culture and Inland Fisheries, Agricultural University, Wageningen, Netherlands. Present address: Organization for Improvement of Inland Fisheries, P.O. Box 433, 3430 AK Nieuwegein, Netherlands)

Accepted: 12 January 1984

\begin{abstract}
Trials in fish ponds in Cameroon and in laboratory tanks in the Netherlands suggest that African catfish (Clarias lazera) is highly suitable for aquaculture and can replace Nile tilapia (Sarotherodon niloticus) in African fish farms.
\end{abstract}

Key-words: Clarias lazera, African catfish, fish farming, fish culture, reproduction, feed efficiency, energy metabolism. 